ORIGINAL ARTICLE

\title{
Severity of Alveolar Bone Loss in Control and Uncontrolled Type II Diabetics
}

\author{
AFAQ FAROOQ ${ }^{1}$, MADIHA RIASAT ${ }^{2}$, HAMMAL KHAN NASEER BALOCH ${ }^{3}$, SYEDA GULRUKH SABA SHAH ${ }^{4}$, SOFIA \\ SHEHZAD ${ }^{5}$, SYEDA ZILI-E-HARAM SABA SHAH ${ }^{6}$ \\ ${ }^{1}$ Assistant Professor, Department of Periodontology, Sardar Begum Dental College Gandhara University, Peshawar \\ ${ }^{2}$ Assistant Professor, Department of Periodontology, Khyber Medical University, Kohat \\ ${ }^{3}$ Associate Professor, Department of Community \& Preventive Dentistry, Dental Section, Bolan Medical College Quetta \\ ${ }^{4}$ Assistant Professor, Department of Anatomy, Sardar Begum Dental College Gandhara University, Peshawar \\ 5 Professor of Community Dentistry, Sardar Begum Dental College Gandhara University, Peshawar \\ ${ }^{6}$ M. Phil Scholar, Department of Physiology, Khyber Medical University, Peshawar \\ Correspondence to: Dr. Syeda Gulrukh Saba Shah, Email: gulrukhsaba321@gmail.com, Cell 0336-9678030
}

\begin{abstract}
Objective: To assess the association between the controlled and uncontrolled type-2 diabetic patients to the severity of Alveolar bone loss

Study Designed: Cross-sectional analytical study.

Place and Duration of Study: Department of Radiology, Sardar Begum Dental College and Khyber College of Dentistry Peshawar KPK from $1^{\text {st }}$ October 2020 to $31^{\text {st }}$ March 2021.

Methodology: One hundred and seventy patients were included. Daniel formula (1999) was used for the patient to check the alveolar bone loss and questionnaire was filled by the researcher and examination was done on the dental unit using examination instruments.

Results: The mean age was $39.41 \pm 6.92$. The oral hygiene status in patients visiting the radiology department using toothpaste twice a day was $50.58 \%$ while bone loss among patient using toothpaste and brushing their teeth twice a day was $21.51 \%$. The patient with a controlled glucose level was $41.28 \%$ while a patient with an uncontrolled glucose level was $58.72 \%$. The bone loss in a patient with controlled $\mathrm{HbA} 1 \mathrm{c}$ the bone loss in normal to moderate $38.38 \%$ while severe bone loss was $2.90 \%$ which is less as compared to the controlled group. The bone loss was reported higher in males (51.16\%)as in females were $48.84 \%$, but there was a severe bone loss in females $31,40 \%$ as compared to males $17.44 \%$.

Conclusion: There is a strong association between alveolar bone loss with the increased level of $\mathrm{HbA1c}$. When the levels of $\mathrm{HbA1c}$ level increased the bone loss in both male and female was reported high. Type 2 diabetic patients having increased $\mathrm{HbA} 1 \mathrm{c}$ levels cause severe bone loss.
\end{abstract}

Keywords: Diabetes mellitus, Out-patient department, Hemoglobin A1c

\section{INTRODUCTION}

Periodontitis and gingivitis are inflammatory diseases and have an effect on the attachment apparatus of the teeth and leads to gingival inflammation, connective tissues loss and formation of the periodontal pockets, resorption of the alveolar bone and finally the loss of the tooth are the ultimate resulting. Conditions that are local and systemic can affect the progression of the periodontal infection. Plaque a local cause can be included, calculus, faulty restorations which may be damaged or improperly restored. ${ }^{1}$ The world health organization reported that about $10-15 \%$ of the world population have periodontitis. ${ }^{2} \mathrm{~A}$ bacterial plaque influences the periodontal infection, in which the host response is stimulated. The response of the inflammation is categorized by the inflammation of mediators derived from host dysregulated secretion and the breakdown of the tissues. Further, the wide range of studies reported IL-6, IL-1 $\beta$, prostaglandin E2 (PGE2), TNF- $\alpha$, matrix metalloproteinases (MMPs; particularly MMP-8, MMP-9 and MMP-13), receptor activator of nuclear factor-kB ligand (RANKL), and also cytokines which regulate the T cells, for example, IL-12, IL-18 and the chemokines receptors. ${ }^{3}$

Lymphocyte and neutrophil migration occurs in the progression of the initial disease to the place of the microbial offence. Further, as the disease spreading become recognizable, the influx of plasma cell, macrophage and the destruction of the collagen protein can be observed. ${ }^{4}$

In diabetic patients in 2003, the American Dental Association (ADA) recognized the presence of periodontal disease. People having type-1 Diabetes mellitus have poor metabolic regulation which increases the risk of periodontitis. ${ }^{5}$ More than one-quarter of people were reported who have poor metabolic regulation have lost $5 \mathrm{~mm}$ of bone or greater as compared with the 10 percent of people who have good metabolic regulation. Periodontal disease prevalence is more common in patients having diabetes than the patients having no diabetes. ${ }^{6}$ Grossi and others ${ }^{7}$ reported in a huge cross-sectional study that the attachment loss was twice in diabetic patients as compared to the normal patients. The clinical attachment loss is significant as compared to the control patients.

The major risk factor for causing periodontitis is diabetes. ${ }^{8}$ In diabetic patients, the risk of getting periodontitis is three-time higher as compared to nondiabetic patients. ${ }^{9}$ According to the National Health and Nutrition Examination Survey (NHANES), III in the united states $\mathrm{HbA} 1 \mathrm{c}$ level of $>9 \%$ in adults had a significantly greater prevalence of severe periodontitis compared to the patients having no diabetes. ${ }^{10}$ In 1990, in the Pima Indian population, numerous cross sectionals and longitudinal studies confirmed that diabetes is the major risk factor causing periodontitis. The patients having type- 2 diabetes 
mellitus have a high prevalenceof periodontitis as compare to the patients having no diabetes in the Pima Indians. ${ }^{11}$ In the Pima Indians, periodontitis risk was reported three times more in diabetic patients. ${ }^{12}$

Diabetes mellitus type- 2 is a greater risk factor for periodontitis, possibly, because the history of both diseases tended to appear in the 40-50 age of the patients. Though diabetes mellitus type- 1 can also increase the risk of causing periodontitis, however, the risk of periodontitis is also increased by diabetes and in every age. ${ }^{13}$

In recent research, it was reported that 350 diabetic children's age from 6 to 8 years are compared with the normal children's having no diabetes the chance of periodontitis was reported greater in the children's having diabetes. ${ }^{14}$ The dentists are conscious about the diabetes patient's diagnosis, which have several complications in the oral infection which comprises candidal infections, xerostomia and periodontitis. In the 1990s it was considered sometime that periodontitis is the $6^{\text {th }}$ major complication of diabetes but in 2003 the ADA confirm the periodontitis found frequently in patients having diabetes. ${ }^{15}$

The high concentration of glucose in the fluid of gingival crevicular is due to the levels of glucose high in the plasma and it weakens the capacity of healing in fibroblasts of the periodontium, which is responsible for the health maintenance of the tissues. Further, Frantzis et $\mathrm{al}^{16}$ reported the gingival capillaries thickness increase in the patients having diabetes which possibly limit the diffusion of the nutrients and the oxygen supply and that causes the immune capacity to limited in the periodontal tissues. Finally, the microbial response is boosted by the reduced amount of collagen production and diabetic degradation. ${ }^{17,18}$

The current research focuses on the Alveolar bone loss severity in patients having controlled and uncontrolled diabetes. The present study investigates the patients having type- 2 diabetes and its association with bone loss in district Peshawar dental hospitals so that special consideration for the treatment of diabetic patients should be made and to counsel the patients about the oral hygiene measures. The main objective of the study is to assess the association between the controlled and uncontrolled type-2 diabetic patients to the severity of Alveolar bone loss.

\section{MATERIALS AND METHODS}

This cross-sectional analytical study was conducted in the radiology department of Sardar Begum Dental College and Khyber College of Dentistry Peshawar from $1^{\text {st }}$ October 2020 to $31^{\text {st }}$ March 2021 and 172 individual were enrolled. Patients under treatment or had diabetes mellitus diagnosed for at least five years or more, Not having any other systemic disease,. not having any history of diabetic complications like neuropathy, nephropathy, retinopathy, not using drugs such as phenytoin, nephidipine, cyclosporine and calcium channel blockers were included. Pregnant and lactating mothers were excluded.

A diabetic patient with pain in molars was selected for the determination of glucose levels. The blood sample was collected from the patient using a DB5ml disposable syringe (Becton Dickinson Pakistan Private Limited 10km Sheikhupura Road Muridke) in strict sterile conditions. The collected blood sample was labelled properly according to the patient record in the hospital. The $\mathrm{HbA1c}$ test was performed for each individual. The results of the $\mathrm{HbA1c}$ tests were categorised into two groups; (1) mild $<7 \%$ was reported as control and (2) moderate and Severe $>7.0 \%$ were reported as uncontrolled.

The parallelism technique of the periapical X-ray was used to record the bone level distally and mesially. The reported bone loss will be recorded in millimetres, the CEJ and the alveolar bone crest distance from each other, and also the CEJ and the apex of root distance between them were recorded. To find the percentage of bone loss the reported distances were multiplied by 100. The CEJ and alveolar bone distance between them was represented by $1 \mathrm{~mm}$ thickness. The point at which the intact lamina along the root was defined was the bone crest level. The data was entered and analyzed through SPSS-20. The Chisquare test was applied.

\section{RESULTS}

The mean age was $39.41 \pm 6.92$ years. There were 88 $(51.1 \%)$ males while $84(48.9 \%)$ were females. The frequent uses of oral hygiene patients are $50.8 \%$ which uses toothpaste more than twice a day and $21.5 \%$ of patients using frequent toothbrush twice a day are normal to moderate in bone loss while patients having no oral hygiene, use is $21.4 \%$ and are severe in bone loss. The controlled glucose level patients are $41.3 \%$ while the uncontrolled glucose level patients are $58.7 \%$. Normal to moderate patients were $78.8 \%$ and severe patients $21.2 \%$ (Table 1).

The patients having control $\mathrm{HbA} 1 \mathrm{c}$ levels have bone loss in normal to moderate $38.38 \%$ while the ratio of severing is low $2.90 \%$. In uncontrolled $\mathrm{HbA} 1 \mathrm{c}$ levels, the frequency of normal to moderate is $35.46 \%$ while the severe ratio is very high $23.26 \%$, statistically the difference was significant $(P=0.000)$ [Table 2]. The correlation of gender with the $\mathrm{HbA} 1 \mathrm{c}$ and bone loss was presented in table 6 . The total bone loss was reported higher $51.16 \%$ in male while the females are $48.84 \%$, but the severe in bone loss female were reported higher $17.44 \%$ while the male was $8.72 \%$ and the moderate ratio of the male is $42.44 \%$ and female are $31.40 \%$, the significance of bone loss in gender-wise correlation is not quite prominent (Table 3 ).

Table 1: Demographic information of the patients $(n=172)$

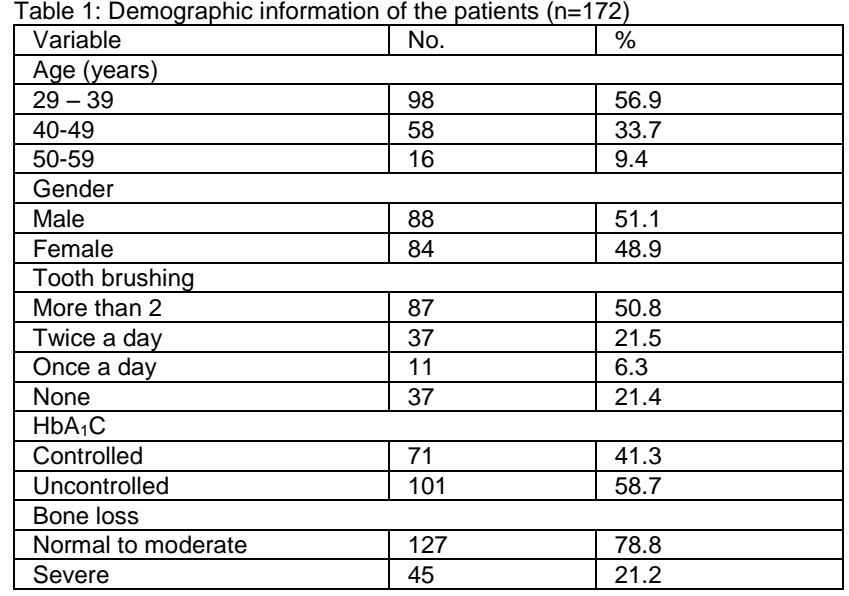


Table 2: $\mathrm{HbA} 1 \mathrm{c}$ and bone loss cross-correlation

\begin{tabular}{|c|c|c|c|c|}
\hline \multirow[b]{2}{*}{ HbAlc } & \multicolumn{2}{|l|}{ Bone Loss } & \multirow[b]{2}{*}{$\chi^{2}$ Value } & \multirow[b]{2}{*}{$\begin{array}{l}P \\
\text { value }\end{array}$} \\
\hline & $\begin{array}{l}\text { Normal to } \\
\text { moderate }\end{array}$ & Severe & & \\
\hline Controlled & 66 (38.38\%) & $5(2.9 \%)$ & \multirow{2}{*}{22.993} & \multirow{2}{*}{0.000} \\
\hline Uncontrolled & $61(35.46 \%)$ & $40(23.26 \%)$ & & \\
\hline
\end{tabular}

Table 3: Gender correlation with the HbA1c and bone loss

\begin{tabular}{|c|c|c|c|c|c|}
\hline \multirow[b]{2}{*}{ Gender } & \multirow[b]{2}{*}{ HbAlc } & \multicolumn{2}{|l|}{ Bone Loss } & \multirow[b]{2}{*}{$\begin{array}{l}\chi^{2} \\
\text { Value }\end{array}$} & \multirow{2}{*}{$\begin{array}{l}P \\
\text { valu } \\
\mathrm{e}\end{array}$} \\
\hline & & $\begin{array}{l}\text { Normal to } \\
\text { moderate }\end{array}$ & Severe & & \\
\hline \multirow[b]{2}{*}{ Male } & Controlled & $37(21.51 \%)$ & $3(1.74 \%)$ & \multirow[b]{2}{*}{4.725} & \multirow[b]{2}{*}{$\begin{array}{l}0.03 \\
0\end{array}$} \\
\hline & Uncontrolled & $36(20.93 \%)$ & $\begin{array}{l}12 \\
(6.98 \%)\end{array}$ & & \\
\hline \multirow[b]{2}{*}{ Female } & Controlled & $29(16.86 \%)$ & $2(1.16 \%)$ & \multirow[b]{2}{*}{$\begin{array}{l}18.32 \\
5\end{array}$} & \multirow{2}{*}{$\begin{array}{l}0.00 \\
0\end{array}$} \\
\hline & Uncontrolled & $25(14.53 \%)$ & $\begin{array}{l}28 \\
(16.28 \%)\end{array}$ & & \\
\hline
\end{tabular}

\section{DISCUSSION}

The patients having uncontrolled glucose levels of blood in type-2 diabetes have more alveolar bone loss. The significant value of the study is $p=0.0001$, which suggested that the alveolar bone loss and $\mathrm{HbA1c}$ high levels have a strong association. In 2002, an epidemiological study has been conducted by Tsai et $\mathrm{al}^{10}$ and Tylor et $\mathrm{al}^{11}$ reported that the patients having low glucose level in the blood while having diabetes type-2 have an increased risk of severe periodontal loss. Hyperglycemia individuals having diabetes type-2 with uncontrolled blood glucose levels have more alveolar bone loss as compare to the patients having the same diabetes type- 2 but controlled blood glucose levels. The categories for the levels of $\mathrm{HbA} 1 \mathrm{c}$, and the tooth brushing frequency of the Tylor, Hayes and Tsai were the same as compared to the current study. The current study also suggested that the individuals having frequent use of oral hygiene have normal to moderate bone loss while the patients having no oral hygiene have severe bone loss in both male and female. The current research also supports that the patients having uncontrolled diabetes type-2 have severe and more bone loss as compare to the patients having diabetes type-2 but controlled levels of glucose in the blood.

In 2011, Persson ${ }^{19}$ conducted a survey which stated that if the $\mathrm{HbA} 1 \mathrm{c}$ levels increases in blood the bone loss will be severe and more as compared to the controlled blood glucose levels patients. The results of the survey also supported the current study results comparing the $\mathrm{HbA1c}$ levels and bone loss in patients, which proves the strong association of $\mathrm{HbA} 1 \mathrm{c}$ levels and bone loss. Another survey was conducted by Asfour et $\mathrm{al}^{15}$ reported the periodontal apparatus disruption in the patients having uncontrolled levels of glucose

In Indonesia, a research study was conducted by Susanto et $\mathrm{al}^{20}$ reported that the patients having diabetes type-2 and uncontrolled levels of glucose in the blood have clinical attachment loss (CAL) more than $4 \mathrm{~mm}$. Becker et $\mathrm{al}^{21}$, Cooper et $\mathrm{al}^{22}$ and Peled et $\mathrm{al}^{23}$ also reported that when the patients have diabetes type- 2 with uncontrolled $\mathrm{HbA1c}$ levels in the blood, the survival rates of the patients get reduced because of the getting complications in the soft tissues.

In 2000, Olson et $\mathrm{al}^{24}$ showed that the $\mathrm{HbA1c}$ increase can highly affect alveolar bone loss which further reported the implant failure in the patients having type-2 diabetes and uncontrolled glucose levels. The same results can be observed in the Khader et $\mathrm{al}^{26}$ study in 2006 which showed that the diabetic patients were highly significant in bone loss to compare to non-diabetic patients which leads them to poor periodontal health.

Sandberg and Wikbland ${ }^{26}$ reported that diabetic patients were poor in oral health as compared to the nondiabetic patients. The patients having diabetes mouth were also dry which supports our findings also that the heath of the periodontal, comprises periodontal ligaments which are intact, and the alveolar bone was highly affected in the presence of high glucose level in blood. The results of Matu et $\mathrm{al}^{27}$ in 2009 were also similar, they reported that the patients with hyperglycemia having periodontal disease shows severe loss of attachment for example the alveolar bone loss and the detachment of periodontal fibres. As reported in the current study results that the association is very strong between the patients having uncontrolled diabetes and bone loss both in male and female whereas a similar study is conducted by Rajhans et $\mathrm{al}^{28}$, in which both the male and female patients were suffering from periodontists.

Another study conducted by Shimazaki et $\mathrm{al}^{29}$ and reported hat the intolerance of glucose directly links with the inflammation severity in the attachment body part of the teeth. Even after the strong link representation between the alveolar bone loss in adiabatic patients having type-2. Bacic et $\mathrm{al}^{30}$ reported that the need for treatment is lower in both the adiabatic and non-adiabatic patients. .As comparing all reported studies results with the current study results it was concluded that patients having diabetes type-2 and the glucose levels are uncontrolled in the blood, the alveolar bone loss is a severe condition. While a patient with diabetes and have regular oral hygiene are at low or moderate risk of bone loss while the non-oral hygiene patients are at the severe condition of bone loss.

\section{CONCLUSION}

For periodontitis disease, the major risk factor is diabetes, confirmed by several epidemiological investigations. When the glucose levels in the blood are uncontrolled, the risk becomes higher for periodontitis: patients with poorly controlled diabetes are at increased risk for microvascular and macrovascular complications with periodontitis and alveolar bone loss.

\section{REFERENCES}

1. Socransky S, Haffajee A, Cugini M, Smith C, Kent R Jr. Microbial complexes in subgingival plaque. J Clin Periodontol 19998; 25(2): 134-44.

2. Löe $H$, Theilade $E$, Jensen SB. Experimental gingivitis in man. J Periodontol 1985; 36(3): 177-87.

3. Löe H, Anerud A, Boysen H, Morrison E. Natural history of periodontal disease in man: rapid, moderate and no loss of attachment in Sri Lankan laborers 14 to 46 years of age. J Clin Periodontol 1986; 13(5): 431-40.

4. Jain S, Darveau RP. Contribution of porphyromonas gingivalis lipopolysaccharide to periodontitis. Periodontology 2010; 54(1): 53-70.

5. Champagne CM, Buchanan W, Reddy MS, Preisser JS, Beck JD, Offenbacher S. Potential for gingival crevice fluid measures as predictors of risk for periodontal diseases. Periodontology 2003; 31(1): 167-80.

6. Niederman R, Westernoff T, Lee C, Mark L, Kawashima N, Ullman-Culler $M$, et al. Infection-mediated early-onset 
periodontal disease in P/E-selectin-deficient mice. J Clin Periodontol 2001; 28(6): 569-75.

7. Assuma R, Oates T, Cochran D, Amar S, Graves D. IL-1 and TNF antagonists inhibit the inflammatory response and bone loss in experimental periodontitis. J Immunol 1998; 160(1): 403-9.

8. Chávarry NGM, Vettore MV, Sansone C, Sheiham A. The relationship between diabetes mellitus and destructive periodontal disease: a meta-analysis. Oral Health Preventive Dentistry 2009; 7(2):.

9. Mealey BL, Ocampo GL. Diabetes mellitus and periodontal disease. Periodontology 2007; 44(1): 127-53.

10. Tsai C, Hayes C, Taylor GW. Glycemic control of type 2 diabetes and severe periodontal disease in the US adult population. Community Dentistry Oral Epidemiol 2002; 30(3): 182-92.

11. Taylor GW, Burt BA, Becker MP, Genco RJ, Shlossman M. Glycemic control and alveolar bone loss progression in type 2 diabetes. Ann Periodontol 1998; 3(1): 30-9.

12. Emrich LJ, Shlossman M, Genco RJ. Periodontal disease in non-insulin-dependent diabetes mellitus. J Periodontol 1991; 62(2): 123-31.

13. Cianciola L, Park B, Bruck E, Mosovich L, Genco R. Prevalence of periodontal disease in insulin-dependent diabetes mellitus (juvenile diabetes). J Am Dent Assoc 1982; 104(5): 653-60.

14. Lalla E, Cheng B, Lal S, Kaplan S, Softness B, Greenberg E, et al. Diabetes mellitus promotes periodontal destruction in children. J Clin Periodontol 2007; 34(4): 294-8,

15. Asfour M, Lambourne A, Soliman A, Al-Behlani S, Al-Asfoor D, Bold A, et al. High prevalence of diabetes mellitus and impaired glucose tolerance in the Sultanate of Oman: results of the 1991 national survey. Diabetic Med 1995; 12(12): 1122-5.

16. Frantzis TG, Reeve CM, Brown AL Jr. The ultrastructure of capillary basement membranes in the attached gingiva of diabetic and nondiabetic patients with periodontal disease. $J$ Periodontol 1971; 42(7): 406-11.

17. Pourhoseingholi MA, Vahedi M, Rahimzadeh M. Sample size calculation in medical studies. Gastroenterol Hepatol 2013; 6(1): 14.

18. Teeuw WJ, Gerdes VE, Loos BG. Effect of periodontal treatment on glycemic control of diabetic patients: a systematic review and meta-analysis. Diabetes Care 2010; 33(2): $421-7$.
19. Persson GR. Diabetes and periodontal disease: an update for health care providers. Diabetes Spectrum 2011; 24(4): 195-8.

20 Susanto $H$, Nesse W, Dijkstra PU, Agustina D, Vissink A, Abbas F. Periodontitis prevalence and severity in Indonesians with type 2 diabetes. J Periodontol 2011; 82(4): 550-57.

21 Becker J, Nora DB, Gomes I, Stringari FF, Seitensus R, Panosso JS, et al. An evaluation of gender, obesity, age and diabetes mellitus as risk factors for carpal tunnel syndrome. Clin Neurophysiol 2002; 113(9): 1429-34.

22. Cooper JD, Smyth DJ, Smiles AM, Plagnol V, Walker NM, Allen JE, et al. Meta-analysis of genome-wide association study data identifies additional type 1 diabetes risk loci. Nature Genetics 2008; 40(12): 1399.

23. Peled M, Ardekian L, Tagger-Green N, Gutmacher Z, Machtei EE. Dental implants in patients with type 2 diabetes mellitus: a clinical study. Implant Dent 2003; 12(2): 116-22.

24. Olson JW, Shernoff AF, Tarlow JL, Colwell JA, Scheetz JP, Bingham SF. Dental endosseous implant assessments in a type 2 diabetic population: a prospective study. Int $\mathrm{J}$ Oral Maxillofacial Implants 2000; 15(6): 81118.

25. Khader YS, Dauod AS, El-Qaderi SS, Alkafajei A, Batayha WQ. Periodontal status of diabetics compared with nondiabetics: a meta-analysis. J Diabetes Complications 2006; 20(1): 59-68.

26. Sandberg GE, Wikblad KF. Oral health and health-related quality of life in type 2 diabetic patients and non-diabetic controls. Acta Odontologica Scandinavica 2003; 61(3): 1418.

27. Matu N, Stephen L, Lalloo R. Prevalence and severity of periodontal disease: type 2 diabetics versus non-diabetics: scientific. South Afr Dent J 2009; 64(2): 64-8.

28. Rajhans NS, Kohad RM, Chaudhari VG, Mhaske NH. A clinical study of the relationship between diabetes mellitus and periodontal disease. J Indian Soc Periodontol 2011; 15(4): 388

29. Saito T, Shimazaki Y, Kiyohara Y, Kato I, Kubo M, lida M, Koga $T$. The severity of periodontal disease is associated with the development of glucose intolerance in nondiabetics: the Hisayama study. J Dent Res 2004; 83(6): 48590.

30. Bačić M, Ciglar I, Granić M, Plančak D, Šutalo J. Dental status in a group of adult diabetic patients. Community Dent Oral Epimediol 1989; 17(6): 313-6. 